\title{
TRUTH: A Concept Unlike Any Other
}

\author{
Jamin Asay \\ The University of Hong Kong \\ asay@hku.hk
}

Forthcoming in Synthese

\begin{abstract}
This paper explores the nature of the concept of truth. It does not offer an analysis or definition of truth, or an account of how it relates to other concepts. Instead, it explores what sort of concept truth is by considering what sorts of thoughts it enables us to think. My conclusion is that truth is a part of each and every propositional thought. The concept of truth is therefore best thought of as the ability to token propositional thoughts. I explore what implications this view has for existing accounts of concepts (such as prototypes, exemplars, and theories), and argue that truth is a concept unlike any other.
\end{abstract}

\section{Introduction}

What is the concept of truth? In asking this question, I am not raising one of the more familiar questions pursued by most philosophers discussing truth. I am not asking what it is for something to be true, offering an analysis of what property it is that makes something true, or investigating the conceptual ties between truth and other concepts. Rather, I am honing in on one particular aspect of the overall theory of truth that receives far less attention. My concern is with the concept of truth (hereafter 'TRUTH'), and specifically with what sort of thing it is. Many writers discuss TRUTH, and distinguish it from the property (or properties, according to alethic pluralists) of truth and words like 'true', 'verdad', and 'wahr'. However, I do not intend to explore how or whether TRUTH can be analyzed into further concepts. My question is, rather, an ontological one that requires an investigation into the nature of concepts in general, and what implications those theories and TRUTH have for one another. In referring to the concept of truth, I am assuming that my target is a shared and uniform one, belonging to cognitive agents regardless of their language 
or even species. ${ }^{1}$ As will emerge, I take TRUTH to be a concept necessary for any kind of propositional thought whatsoever.

By inquiring into the nature of the concept of truth, one might be looking for a definition or analysis. Some views define TRUTH in terms of other concepts, such as CORRESPONDENCE or COHERENCE; others argue that it cannot be so defined because it is primitive or fundamental (e.g., Davidson 1996, Patterson 2010, and Asay 2013). Deflationists reject the very search for such a definition, judging substantive analysis into the nature of truth to be misguided and premised on a mistaken and inflated perspective of the philosophical importance of the concept (e.g., Horwich 1998). Again, this is not my concern. Though it concerns the concept of truth, my investigation is ontological, rather than being purely conceptual. That is to say, instead of looking at conceptual connections between TRUTH and other concepts, I am looking at TRUTH itself. What is it? What sort of concept is it? What does it take to have it, and what does having it enable one to do? There are various general theories of concepts, according to which they are mental representations, abstract entities, abilities, etc. My aim is to explore how TRUTH fits in with these various theories of concepts, and what implications they have for each other.

My titular hypothesis is that TRUTH is a concept unlike any other. It has features that general theories of concepts have difficulty accounting for, as it turns out to be quite different from most ordinary concepts_-even those of perennial philosophical interest. Exploring and uncovering this idiosyncratic nature of TRUTH is my main goal in this paper.

\section{Truth and TRUTH}

Drawing distinctions between properties and concepts is a welcome philosophical commonplace nowadays, and the distinction between the property of truth (hereafter 'truth') and TRUTH has informed much current theorizing in the theory of truth. ${ }^{2}$ William Alston, for instance, writes:

\footnotetext{
${ }^{1}$ This assumption is consistent with those pluralist views about truth that find plurality among truth properties but unity in the concept (e.g., Wright 1992 and Lynch 2009). If, as on Kölbel's view (2008, 2013), our truth-related talk and thought is ambiguous in a way that suggests there are multiple truth concepts, then my conclusions apply to whichever of those concepts is governed by the various alethic phenomena I invoke in my arguments.

2 See, e.g., Wright 1992, 1996, and 2013, Sosa 1993, Alston 1996 and 2002, Bar-On and Simmons 2007, Lynch 2009, and Asay 2013. To get a taste for philosophizing without a clear concept/property distinction, turn to the opening sections of Principia Ethica (Moore 1903).
} 
it may be that the property of truth really is what is specified in one or another version of the correspondence theory, even though, on my view and other "minimalist" views, the concept we wield in ordinary thought and talk when saying of a proposition, statement, or belief that it is true does not specify any mode of "correspondence" with a fact, a truth maker. (2002: 11)

The idea here is that the property truth might not be "metaphysically transparent", which is to say that the nature of truth is not disclosed simply by way of grasping the concept TRUTH (Lynch 2009: 107). A classic illustration of non-transparency is the property being water to be made out of water is to be made out of $\mathrm{H}_{2} \mathrm{O}$ molecules, but this a posteriori fact about the property being water is not accessible merely by a priori reflection upon WATER. The view Alston suggests maintains that there may be more to truth than is revealed by a priori inspection of TRUTH. Though I disagree with Alston's particular perspective on truth and TRUTH, I gladly follow him in separating the two distinct inquiries.

Another crucial distinction in the theory of truth is between theories that are substantive and those that are deflationary. With respect to the property truth, one might defend either a substantive view or a deflationary one. What it is for a theory of truth to be deflationary or not is a matter of some debate. Edwards (2013) and Asay (2014), for instance, construe the debate as being over whether truth is a sparse or an abundant property. In Lewis's (1983) terms, sparse properties are the metaphysically interesting properties that are causally and explanatorily relevant, that "carve nature at the joints". Abundant properties, by contrast, are metaphysically superfluous, explanatorily speaking. (Consider the disjunctive property being a bachelor, not blue, or within 4.2 kilometers of a pangolin.) Though I shall not defend it here, I incline toward the deflationary view that truth is a merely abundant property: it does not reside among the sparse properties that play substantive theoretical roles in metaphysical inquiry, regardless of whether sparse properties are understood in terms of universals, tropes, natural classes, or something else. This metaphysically deflationary view is distinct from conceptually deflationary views about TRUTH, which maintain that truth is an explanatorily uninteresting concept that does not need significant philosophical analysis. (Thoroughgoing deflationists such as Paul Horwich (1998) subscribe to both theses.) For the metaphysical deflationist, truths are not true in virtue of instantiating some metaphysically substantive alethic property (such as corresponding with the facts, cohering with an ideal set of beliefs, or being usefully believed). Rather, 'Snow is white' is true because snow is white, 'Grass is green' is true because grass is green, and so forth. 
Just as one might defend a view about truth without taking a stand on the nature of properties in general (e.g., whether or not properties are universals or tropes), one might defend a view about TRUTH that explores its most important features, but without taking on a particular view as to what concepts in general are (e.g., Scharp 2013: 35). For example, one might analyze TRUTH in terms of COHERENCE, but without presupposing any particular view as to whether concepts in general are abilities, mental representations, abstract entities, or something else. In this paper, I demonstrate why that kind of neutrality needs to be questioned, once we reflect on some of the basic roles that TRUTH performs in our cognitive architecture.

\section{Theorizing with Concepts}

Even for those philosophers who draw the distinction between truth and TRUTH, it's not terribly clear what is involved in giving a theory of the concept TRUTH. For many, of course, giving a theory of TRUTH is just giving a definition or analysis of TRUTH (or explaining why no such definition or analysis can or need be given). In what may or may not amount to the same thing, Alston implies that giving a theory of the concept of truth is to give a theory of the meaning of the word 'true' (1996: 228). Other philosophers seem to be thinking of the project of giving an account of the concept of truth to be one of identifying and systematizing certain core truisms, platitudes, or a priori principles about truth (e.g., Wright 1992 and Lynch 2009). These sorts of inquiry are all familiar to truth theorists. What I wish to explore are questions about TRUTH that emerge from thinking about the nature of concepts in general. Accordingly, I turn now to some basic facts and theories about the nature of concepts, in the interest of seeing how TRUTH does or doesn't fit with familiar thinking about concepts generally.

As with most topics in philosophy, the discussion around the nature of concepts is vexed. It's controversial what concepts are, what form a theory of concepts should take, how philosophical thinking about concepts does or doesn't intersect with psychological thinking about concepts, and even whether concepts deserve a place in the proper study of the mind. ${ }^{3}$ While this paper is not the place to settle any of these longstanding debates, I shall nevertheless try to import a number of relevant inquiries that arise in the theory of concepts to the study of TRUTH. To wit, I shall be raising and exploring each of the following familiar questions about concepts, but applied to TRUTH in particular:

\footnotetext{
${ }^{3}$ See Machery 2009 for an overview of much current thinking about concepts in philosophy and psychology, and a negative answer to the final question stated here.
} 
(1) What thoughts does TRUTH enable us to think?

(2) What sort of thing is TRUTH?

(3) What relations does TRUTH bear to 'true', 'truth', etc.?

(4) What is the structure of TRUTH?

(5) What is involved in possessing TRUTH?

These questions do not exhaust everything there is to say about TRUTH, but coming to some defensible views about them will take the theory of truth deeper into the nature of TRUTH than it often goes. Nor can these questions be handled completely independently of one another. Nevertheless, I shall address these questions in the order listed above, though that order is rather arbitrary, given the connections that hold between them.

First, however, let's consider a few methodological points about the study of concepts. My ultimate ontological question is about what sort of thing TRUTH is. While simple on its face, the question is potentially problematic in a number of ways. According to Edouard Machery, for instance, what a psychologist would identify as TRUTH may not be what a philosopher would identify as TRUTH. The former, says Machery, is a body of knowledge about truth stored in memory that is used by default in cognitive processing of judgments concerning truth (2009: 12). The latter, by contrast, refers to one's ability to have intentional states that are about truth qua truth (2009: 32). Furthermore, according to Machery, there are multiple kinds of concepts (namely, prototypes, exemplars, and theories), and so there is no single thing that can be called (by a psychologist) 'TRUTH'.

Given these complexities, it will be impossible to proceed without begging at least a few questions in the theory of concepts. Nevertheless, my goal is to prepare the space for further interaction between theorists of truth and philosophers and psychologists interested in concepts. To that end, I hope to start from as neutral a starting place as is reasonable and possible. Perhaps the closest thing to a consensus one can come to in the theory of concepts is that, whatever else they are, concepts are the constituents of thoughts (Margolis and Laurence 2014). Jesse Prinz, for instance, begins his book-length study of concepts by writing: "Without concepts, there would be no thoughts. Concepts are the basic timber of our mental lives" (2002: 1). Concepts, on this widely shared view, are the ingredients needed for forming thoughts. If concepts are the constituents of thoughts, then they are mental tools: the things we need in order to have a rich mental life. The more concepts we possess, the more thoughts we can entertain.

Talk of 'thoughts' in this context can be dangerously ambiguous. For example, when I think to myself that snow is white, there is both the state of my thinking that snow is white, and 
also what that thinking expresses, namely, the proposition that snow is white. ${ }^{4}$ Frege (1956) reserves 'thought' (Gedanke) for the latter, but my primary interest is in the former. As I am focused on what's going on in our minds when we're thinking, for example, that snow is white, I shall use 'thought' to refer to the mental states themselves, and 'proposition' to refer to what those mental states express. For the most part, my concentration will be on "propositional thoughts", i.e., those thoughts that express propositions in particular, or are otherwise truth-apt. On occasion I will mention "sub-propositional thoughts", by which I have in mind other mental states that carry conceptual content but aren't truth-apt, such as a mental image of a golden mountain or smiling baby. ${ }^{5}$

Further complicating matters is that thoughts admit of a type/token distinction. When I judge that snow is white, say, I am tokening the same type of thought that Tarski tokened when he judged that snow is white. In order to do so, I maintain, we each need to possess the concept SNOW, among other things; our two concepts of snow are themselves tokens of the same type. Now, there are various metaphysical ways of spelling out what thought tokens, thought types, and propositions are, and how they relate to one another; my aim is to stay neutral on such matters as far as is possible. My guiding idea is that the range of thoughts we can token-be they propositional or sub-propositional-is, in part, a function of which concepts we possess. Hence, I shall be presuming that thoughts are composed by the concepts required to think them. ${ }^{6}$ My plan here is not to offer a theory of the structure of thoughts in general, as that would take us too far afield; my commitment is merely to the claim that whenever possession of a concept is necessary for thinking a certain thought, that is due to the fact that the concept is a constituent of that thought.

\footnotetext{
4 Assuming propositions exist, of course. Those who don't subscribe to propositions should modify my remarks accordingly, as my intent is to be highlighting certain phenomena regarding TRUTH and its role in our thought that still concern the proposition-denier.

${ }^{5}$ I intend to stay neutral regarding just which thoughts are the truth-apt ones (and so, e.g., whether moral judgments express propositional thoughts). I also intend to remain neutral on the issue of whether or not there can be thoughts with non-conceptual content; if there can be such things, they have no bearing on TRUTH.

${ }^{6}$ What composes propositions is therefore a separate matter, and one I shall set aside for present purposes. To my mind, Fregean thinking about propositions coheres perfectly with the idea that which propositions we can express is a function of which concepts we possess. If propositions are composed by concept types (and thus, presumably, identical to thought types), then there is no mystery as to why the set of propositions I can express is a function of which concepts I possess. For those who take propositions to be unstructured sets of possible worlds (e.g., Stalnaker 1976), pleonastic entities (e.g., Schiffer 2003), or Russellian entities composed by objects and properties (e.g., Salmon 1986) it remains to be seen how to bridge the gap between which concepts we have and which propositions we can express.
} 
To investigate TRUTH, then, is to investigate part of the story of how our minds work. By contrast, to investigate truth is to investigate part of the world, and whether it contains such a property. So while the property truth (at least for some philosophers) has a role to play in explaining why truth-bearers are true, the concept TRUTH plays its role in explaining how we can think thoughts that involve truth. But which thoughts involve truth? Answering this question, I argue, is the key to understanding TRUTH's unique position in our conceptual scheme.

\section{A Theory of TRUTH}

In this section I offer my account of the concept TRUTH that proceeds by answering the five questions posed above. The most important argumentative considerations will arise in connection with (1), and from there answers to the subsequent questions will emerge fairly straightforwardly. What will be developed by the end is an account of TRUTH that reveals its unique status in our cognitive economy.

\subsection{What thoughts does TRUTH enable us to think?}

To think about snow, one needs the concept SNOw. To think about Gettier cases, one needs the concept KNOWLEDGE. What is the domain of thoughts that possession of TRUTH enables us to have? As I shall argue, the best answer to this question is that every last propositional thought requires TRUTH, and so TRUTH is necessary to token any propositional thought whatsoever. If true, this fact reveals that TRUTH is indeed a concept unlike any other, and that many familiar accounts of what concepts are and how they function don't work for TRUTH.

Consider first an ordinary concept like DOG. By possessing DOG, people can entertain thoughts about dogs (qua dogs) such as FRENCH BULLDOGS ARE THE MOST ADORABLE KIND OF DOG and DOGS HATE CATS. ${ }^{7}$ Equipped with DOG, people can classify particular animals as being dogs, and mentally distinguish them from non-dogs. Anyone without the concept can't token thoughts about dogs. In short, DOG lets you think about dogs. Presumably, then, TRUTH lets us think about truth. But what is it to "think about truth"? This is actually a surprisingly difficult question. It's not at all clear what 'truth' refers to here, if anything; TRUTH is not a straightforwardly empirical concept like CAT and DOG. In speaking about truth we might be referring to a property: truth is the property of corresponding with the facts, perhaps. We might be referring to things that

\footnotetext{
7 To preserve continuity between concepts and thoughts, I use small-caps sentences to name thoughts. I use ' $<p>$ ' later on in the standard way as a name for the proposition that $p$.
} 
have that property, i.e., truths: the English sentence 'Snow is white', my belief that seven is prime, or the proposition that Hume died in 1776. We might, if we're in a Fregean mood, be referring to an object that we take to be the referent of all true sentences (Frege 1952). We might be referring to certain linguistic constructions such as the predicate 'is true' and the sentential prefix 'it is true that', or applications thereof. We might just be talking about TRUTH, as, perhaps, when philosophers of language say things like 'truth and meaning are inextricably linked'.

We are already mired in a number of controversies. All sorts of challenges have been raised against the ontological credibility of certain kinds of truth-bearers, the property truth, and Frege's 'the True', and it's a matter of enormous dispute whether or not there's anything more to truth than the expressive utility provided by 'is true'. Hence, there is no straightforward answer to the question of what it means to say that possessing TRUTH enables us to think about truth.

In order to press forward in spite of the volatility of the terrain, let me offer the following modest proposal. If we seek to understand TRUTH primarily by way of its role as an enabler of thoughts, then let's consider some potential paradigm cases of thoughts that TRUTH allows us to think. My suggestion is that the following sentences express thoughts for which we need TRUTH, if indeed any sentences do at all:

(A) The sentence 'Snow is white' is true.

(B) It is true that Macau is a special administrative region of China.

(A) results from an application of the predicate 'is true' to the name of a truth-bearer. (B) results from appending the sentential prefix 'it is true that' to a declarative sentence. ${ }^{8}$

Consider (A) first. What it expresses appears to be an ordinary predicative thought, much like Pluto is A DOG and Garfield LiKes LASAgna. ${ }^{9}$ One might argue, therefore, that just as we need DOG to think that Pluto is a dog, so too do we need TRUTH to think that 'Snow is white' is true. According to this line of thought, TRUTH is a familiar kind of "lexical" concept; that is to say, it is a concept that straightforwardly corresponds to a lexical item ('true') in natural language, just as DOG matches up with 'dog' (Laurence and Margolis 1999: 4). According to this view, TRUTH

\footnotetext{
${ }^{8}$ Note that I do not intend anything theoretically loaded in using the terms 'predicate' and 'sentential prefix' here; I am attending only to the surface grammar of sentences. The claims are simply that 'is true' appears to be the predicate in an ordinary subject-predicate sentence, and that 'it is true that' has been appended to the front of a declarative sentence to result in a further declarative sentence.

${ }_{9}^{9}$ But see prosententialism (e.g., Grover 1992), and Strawson's expressivism (1949). Though proponents of these views would surely take issue with many of my claims in this paper, I must set aside discussion of them for another day.
} 
corresponds to 'true', and so, presumably, contributes to the composition of propositional thoughts by way of being a component of predicative thoughts that attribute truth to truth-bearers. What (B) appears to express is something similar to thoughts like IT IS KNOWN THAT FERMAT'S LAST THEOREM CAN BE PROVED. To think that thought, one would need to have the concept KNOWLEDGE; by parallel reasoning, one would need TRUTH to think (B).

The view I'm articulating (but not defending) here regards TRUTH as a straightforward lexical concept, such that the thoughts that TRUTH provides us are, for the most part, those that are expressed by natural language sentences that employ 'true' and similar words. Call this the 'lexical' view about TRUTH. As natural as this modest view may be, it fails to capture what is most unique about truth. The feature of truth that I have in mind here is (or is closely related to) what Blackburn calls "transparency" (1984) and relates to the reasons why McGinn labels truth "selfeffacing" (2000); it's what deflationists focus on, and leads them to reject more substantive accounts of truth. I intend to be highlighting something uncontroversial about truth, something that both substantivists and deflationists acknowledge. Metaphorically speaking, the idea is that truth ascriptions allow us to "look through" them and stare directly at the world (cf. Künne 2003: 92). Perhaps the most neutral way of putting the point is inferentially. From the fact that the sentence 'Snow is white' is true, I can infer that snow is white. By learning that a sentence (or belief, proposition, etc.) has a particular property, I can learn something about snow. By contrast, consider how from the fact that 'Snow is white' is three words long, I cannot infer anything about the color of snow. Truth, in effect, allows us to move seamlessly between vehicles of meaning (sentences, beliefs, propositions) and the world. If I am committed to the judgment that there is a single even prime number, then I should be committed to the judgment that my belief to that effect (and anything else expressing it) is true.

These inferences cohere with the various truth schemas familiar in the theory of truth (e.g., 'the proposition that $p$ is true if and only if $p$ ' and ' $p$ ' is true if and only if $p$ '). My interest in them is, first, that they reveal that for any propositional thought seemingly "not about truth", there are other propositional thoughts that do appear to be about truth, and that are equivalent to it in some sense. The equivalence, at minimum, is material, though it may be stronger depending on some of the considerations raised later on (and depending on which schema is at issue). For example, possession of my belief that pandas eat bamboo requires possession of the concepts PANDA, EAT, and BAMBOO; but that belief is equivalent to another of my beliefs, my belief that it's true that pandas eat bamboo. This second belief is of the sort that I suggested is "about truth", if indeed any beliefs are. 
On the lexical view of TRUTH, we have two beliefs that are equivalent, though only one involves TRUTH. This consequence is not in and of itself contradictory, since material equivalence does not entail conceptual equivalence. But it does reveal that the tenability of the lexical view, and any other account of TRUTH, turns on the nature of the equivalence between our thoughts that seemingly are about truth, and those that seemingly aren't. That is to say, if the equivalence between beliefs that $p$ and beliefs that it's true that $p$ is much stronger than material equivalence-cognitive or conceptual equivalence, say - then the lexical view must be false, as it treats the two as being semantically quite different. Regardless of how strong the equivalence is, it is at least material, and this equivalence is in need of explanation. The lexical view, on its own, doesn't appear to have the resources to account for why these equivalences hold. Some thoughts that involve truth are (at least materially) equivalent to thoughts that aren't. The lexical view, in effect, must recognize a gulf between these two kinds of thoughts; and by separating them in terms of their conceptual composition, the view thereby makes accounting for their equivalence all the more difficult.

This reflection by no means refutes the lexical view. That said, the equivalences invite us to consider alternative explanations. I think that the best explanation of the phenomena related to the so-called transparency of truth is that certain of these inferences are actually between identical contents. Specifically, consider the equivalence between SNOW IS WHITE and IT'S TRUE THAT SNOW IS WHITE. If these "two" types of thought are actually identical, then we have a straightforward explanation of the transparency of truth. The instances of the schema 'It's true that $p$ if and only if $p$ ' hold because the thoughts expressed on either side of the biconditionals are identical. Furthermore, since I suggested that thoughts of the form IT'S TRUE THAT $P$ are paradigmatic of thoughts that require possession of TRUTH, then any thought that $p$ will likewise require possession of TRUTH, since thoughts that $p$ and thoughts that it's true that $p$ are identical and so cognitively equivalent. As a result, I see the explanation of transparency as one route to recognizing my thesis that TRUTH is a part of all propositional thoughts.

If thoughts that $p$ and thoughts that it's true that $p$ are identical, then the equivalencies captured by the schema 'It's true that $p$ if and only if $p$ ' are the strongest possible. As such, they are sufficient to account for the fact which all views countenance, namely, that thoughts that $p$ and thoughts that it's true that $p$ are at least materially equivalent. Now, one might rightly point out that not all material equivalences are best explained by identity. The thoughts SNOW IS WHITE and SNOW IS WHITE AND $2=2$ are also materially equivalent, but that is no argument that they are identical. The explanation for the material equivalence here is straightforward: conjunctions that include a necessary truth as a conjunct are truth-functionally equivalent to the other conjunct: conjoining a necessary truth to another claim doesn't change the truth value. So appeals to identity 
are not always appropriate. My contention is that it is appropriate in the present case, and that this explanation is not available to the lexical view. ${ }^{10}$

The second lesson I draw from the inferences is that, at least in some minimal sense, all propositional thoughts express truth conditions. Without getting into the controversial details of the terrain, we can at least think of truth conditions as being the conditions under which sentences are true. The sentences 'Snow is white' and 'Schnee ist weiss' share the same truth condition: they're true if and only if snow is white. Hence, the propositional thought SNOW IS WHITE expresses the truth condition for some natural language sentences. In general, propositional thoughts, by their very nature, express truth conditions. To token a (propositional) thought, then, is to express a truth condition. Or, as I would put the point, when we think propositional thoughts, we're thinking about truth (correctly or not). Now, many questions remain, such as whether or not truth conditions in this sense are constitutive of meaning, and whether or not deflationary accounts can accommodate even this minimal notion of a truth condition (see Bar-On, Horisk, and Lycan 2000). Regardless of how these other issues are settled, the fact remains that even when we make a straightforward claim that is not obviously about truth, we are nevertheless making that claim by means of a truth condition; we are, in other words, expressing part of the story about truth.

What these various facts about truth reveal, I contend, is that propositional thoughts, regardless of their specific content, are already entangled with TRUTH. It's one thing to think about snow; it's another to have an idea about whiteness. It's still another thing to think about white snow. All of these sub-propositional thoughts involve possession of SNOW and/or WHITE. But to have an idea of white snow-a classic example of a compound sensory idea in the British empiricist tradition-is not to have the thought SNOW IS WHITE. This propositional thought, like the imagining of white snow, requires both SNOW and WHITE. But it must require something else to distinguish it, something to make it propositional. A thought of white snow is not yet truthevaluable; a thought that snow is white is. What makes the latter, but not the former truthevaluable? I suggest a straightforward reply: the latter, and the latter only, involves TRUTH as a constituent. Adding TRUTH to our thoughts, as it were, brings them into the realm of truth, the realm of the propositional.

So far, I have pointed out that our propositional thoughts that are not obviously about truth are equivalent to thoughts that presumably are, and that all propositional thoughts express truth conditions. When we think propositional thoughts, we think the conditions of truth. These considerations, which I take to be common ground, don't by themselves entail that TRUTH is a

\footnotetext{
${ }^{10} \mathrm{My}$ thanks go to the anonymous referees for the journal for pushing me on this point.
} 
constituent of every propositional thought. But they do show that any cognitive activity that is propositional in nature is intimately connected to truth, and these ties need to be accounted for. My goal is to build the case for taking TRUTH to belong to all propositional thoughts on the basis of showing how doing so produces a coherent and explanatory account of all the many ways truth is implicated in our cognitive activity.

In that spirit, we can approach the matter from another angle. What is it that we do with the contents of our propositional thoughts (i.e., propositions)? We can do many things: assert them, deny them, believe them, hypothesize them, imagine them, know them, etc. This set of fundamental things that we do with propositions are all truth-theoretic: that is to say, they all may be understood in terms of truth. To assert that snow is white just is to present that thought to one's audience as being true. To believe that seven is prime is to judge it to be true that seven is prime. What you believe and what you believe to be true are one and the same. To deny something is to deny its truth. To know that Chicago is in Illinois is to know the truth about something. To hypothesize that the Twins will win the next World Series is to consider its truth; to imagine it is to contemplate, or pretend that it is true. Simply put, when we use propositions, we (attempt to) do things with the truth. That is precisely what unifies the class of propositional thoughts, and distinguishes them from the sub-propositional thoughts.

Now, the ability to token a propositional thought at all must accompany the ability to do something with the proposition it expresses. At the least, one must be able to contemplate a proposition; if one can't contemplate a single proposition, one can't have any propositional thoughts. But what one is doing in the act of contemplating some proposition is contemplating the truth of that proposition. Contemplating the proposition that pangolins are endangered is nothing beyond contemplating its being true that pangolins are endangered. But to be able to contemplate at all (as well as believe, assert, know, hypothesize, deny, etc.), one must have the concept of TRUTH. Someone who lacked any conception of truth would not be able to believe or assert something, since those activities are constituted by their relationship to truth. If you have no concept of what it is for something to be true, you're in no position to assert anything, because asserting something is presenting your thoughts to others as being the truth. A mind that can believe and disbelieve must register the difference between being true and not. I conclude that these considerations reveal that when we have a propositional thought before our mind-any propositional thought—we have TRUTH before our mind.

Let's pause and take stock. I began with the suggestion that we think about the nature of TRUTH by considering which thoughts it enables us to think: which thoughts are "about truth"? The lexical view calls our attention to a number of candidate thoughts, but is silent regarding the 
fact that all our judgments that are not on the surface about truth are nevertheless intimately connected to others that are. That suggests that the lexical view misses, quite fundamentally, just which thoughts require TRUTH. I then argued that TRUTH is necessary for thinking any propositional thought whatsoever. The basis for the argument so far is, first, that the best explanation of the equivalencies captured by the truth schemas is that all propositional thoughts are identical to thoughts that do appear to be about truth. Second, all propositional thoughts express truth conditions, which suggests the idea that whenever we're thinking propositional thoughts, we're thinking about the truth. Finally, the notion of truth is inextricably linked to the various kinds of cognitive and speech acts that we perform with propositions. It's unclear how we could engage in any of those activities if we lacked any conception of truth whatsoever. The role of TRUTH is therefore not to enable us to think some proper subset of our propositional thoughts; rather, it is necessary for thinking each and every propositional thought. TRUTH is what distinguishes propositional thoughts from sub-propositional thoughts. Accordingly, on my view, what it is to "think about truth" is simply to engage in propositional thought.

\subsubsection{Fregean omnipresence}

I am under no illusion that my view might be quite unpalatable on first inspection. My defense of it shall be ongoing, as we consider some of the other core questions concerning the nature of TRUTH. My hope is that a coherent and compelling view, composed by many intersecting and mutually supporting theses, will emerge by the end. To further that goal, it might help to see the view as a descendent of some Fregean thinking about truth.

I have presented TRUTH as being a constituent of every propositional thought, such that possession of any propositional thought requires possession of TRUTH. It is not just those thoughts expressed by sentences that involve explicit predications of truth, but all propositional thoughts whatsoever, that require TRUTH. ${ }^{11}$ This thesis is closely related to one known as the omnipresence of truth, which dates back at least to Frege (1879), and perhaps even to Buridan (see Read 2002). Here is one passage in which Frege presents his omnipresence view:

\footnotetext{
${ }^{11}$ A related thesis, defended by Boghossian (2010), is that the concept PROPOSITION presupposes TRUTH, and so anyone possessed of the former is possessed of the latter. I'm inclined to agree, though I stress that my own thesis is stronger. On Boghossian's view, one cannot token PROPOSITION without possessing TRUTH. On my view, one cannot token a proposition without possessing TRUTH.
} 
It may nevertheless be thought that we cannot recognize a property of a thing without at the same time realizing the thought that this thing has this property to be true. So with every property of a thing is joined a property of a thought, namely, that of truth. It is also worthy of notice that the sentence "I smell the scent of violets" has just the same content as the sentence "it is true that I smell the scent of violets". So it seems, then, that nothing is added to the thought by my ascribing to it the property of truth. (1956: 293)

Recall that Frege uses 'thought' where I use 'proposition', so our theses are not identical (unless thought types just are propositions, which they may well be for Fregeans). So it's worth bearing in mind that Frege's thesis is that TRUTH is a part of every proposition, which I take to be a stronger thesis than my own. In Frege's formal language, each sentence is prefixed with a horizontal mark, which, as Künne puts it, is "a truth-predicate in the guise of 'is identical with the True" (2008: 35). Hence, Frege might render $<$ Kermit is a frog $>$ and $<$ Kermit is blue $>$ as ' $-F k$ ' and ' $-\mathrm{Bk}$ ', respectively. Both thoughts, in effect, claim their own truth (though only one correctly does so). To token these thoughts is not yet to assert or believe them, Frege counsels us, since those kinds of cognitive and speech acts cannot be accomplished merely by tokening their content. To believe that God exists is not to contemplate $<$ I believe that God exists $>$ : to be a theist is not simply to consider being a theist. Presumably, one can believe $<$ God exists $>$ without ever even entertaining $<$ I believe that God exists $>$. Furthermore, to assert that God exists is not merely to contemplate $<$ God exists $>$ or even $<$ It is true that God exists $>$. Frege concludes that what turns a contemplation into an assertion is a change in force, not of content. Assertions put forward thoughts as being true, but they don't do that by predicating truth of thoughts. For Frege, all propositions are predications of truth. But not all predications of truth are assertions.

The tenability of Frege's omnipresence view depends on how one thinks about propositions in general. It's unclear, for instance, what it would mean for TRUTH to belong to all propositions when propositions are, say, sets of possible worlds. Omnipresence is more palatable when it comes to thoughts. According to that species of omnipresence, the contribution TRUTH makes to the composition of thoughts is an indispensable one: it provides a necessary component of each and every propositional thought. There is a second difference with Frege that I wish to highlight. Frege chooses to render all propositional thoughts as predications of truth, but this choice is not mandatory. When I consider the thought that Kermit is a frog, I am certainly engaging in an act of predication: the application of FROG to Kermit. To say that what I'm doing is predicating TRUTH of a truth-bearer (thought, proposition, or otherwise) strikes me as unduly revisionary. To think that Kermit is a frog is not to think about a truth-bearer at all. After all, one might have 
certain views about the nature (or non-existence) of certain kinds of truth-bearers that would make one disinclined to make judgments that implicate the existence of metaphysically contentious truth-bearers.

As I understand omnipresence, then, it is not the thesis that TRUTH is a predicative component of every propositional thought. Hence, there is no identity between a thought and a predication of truth of that thought. However, there is an identity worth noting, and that is between the thoughts expressed by sentences with and without the sentential prefix 'it is true that'. For instance, 'Kermit is a frog' and 'It's true that Kermit is a frog' strike me as expressing the same thought. I don't see how it's possible that one can think of Kermit being a frog (regardless of the force that accompanies it) without thinking of it being true that Kermit is a frog. Hence, I see the thoughts KERMIT IS A FROG and IT'S TRUE THAT KERMIT IS A FROG as one and the same. Tokening one just is tokening the other. In this sense, I echo Frege's idea and claim that 'it's true that' "adds" nothing to our thoughts.

If TRUTH doesn't function as an omnipresent predicate, its contribution to propositional thoughts must be understood in some other way. I recommend that the way that TRUTH is a contribution to every propositional thought is by way of its being a structural or logical component, rather than a kind of "subject matter" component. In other words, TRUTH is not a component of KERMIT IS A FROG in the same way that KERMIT and FROG are. TRUTH does not contribute to KERMIT IS A FROG by way of accounting for what the thought is most straightforwardly about. Instead, it plays its role in accounting for how KERMIT IS A FROG is a propositional thought at all. Without TRUTH, one cannot token KERMIT IS A FROG. To think about Kermit and to think about frogs, one needs KERMIT and FROG. To think, further, that Kermit is a frog, one now needs to employ TRUTH.

A useful comparison can be made with the logical connectives. Some of our thoughts are explicitly about conjunction: CONJUNCTIONS ARE ONE KIND OF COMPOUND PROPOSITIONAL THOUGHT, for example. CONJUNCTION contributes to that thought differently than it does to SNOW IS WHITE AND GRASS IS GREEN. That second thought isn't in any immediate way about conjunctions, but CONJUNCTION plays a crucial role in its composition. If one has no concept of conjunction, one cannot think conjunctive thoughts. Conjunction here plays a logical or structural role in the composition of the thought. The thesis of omnipresence is that TRUTH plays a similar kind of role, except that it plays that role for every propositional thought, whereas CONJUNCTION plays its logical role only within conjunctions.

I admit that I have no developed theory of the distinction between logical-structural components of thoughts and more ordinary content-giving components of thoughts. But that 
there is a distinction worth theorizing about is clear, as it's needed to account for those concepts that don't contribute to the subject matter of a thought, but are nevertheless necessary in order to think the thought. I hope that the case of logical connectives provides a plausible independent example of the distinction at work. Fully accounting for that distinction would involve a comprehensive account of the nature of propositional thoughts, which is beyond the scope of the current paper. Still, I believe we can draw out the parallel between TRUTH and other logical notions in ways that will further illuminate the nature and function of TRUTH.

Just as CONJUNCTION figures differently into CONJUNCTIONS ARE ONE KIND OF COMPOUND PROPOSITIONAL THOUGHT and SNOW IS WHITE AND GRASS IS GREEN, so too does TRUTH figure differently into 'SNOW IS WHITE' IS TRUE and SNOW IS WHITE. The latter is not, in any ordinary sense, "about" truth. Nevertheless—defenders of omnipresence should be quick to point out - it is a truth, it is true, and when you do things with it (like asserting, believing, etc.), you're doing things with respect to its truth (or lack thereof). Still, TRUTH's contribution to SNOW IS WHITE is a logical-structural one. We make this structural point explicit when we say 'It's true that snow is white', though we do not thereby adjust the content of what is being expressed. Hence, the language of redundancy strikes me as appropriate when it comes to 'it is true that'. Appending this expression to our words doesn't change the thought being expressed.

TRUTH makes a different contribution to the thought expressed by 'Snow is white' is true'. Here 'true' does, pace prosententialists, appear as a predicate. As a result, one might more plausibly claim that this thought is "about" truth-it's claiming that a particular truth-bearer is true. In such cases, TRUTH plays a double-duty role, much as CONJUNCTION plays a double-duty role in CONJUNCTIONS ARE COMPOUND THOUGHTS AND DISJUNCTIONS ARE COMPOUND THOUGHTS. I agree with deflationary theorists of truth that the best way to understand such predications of 'true' is to see them as a kind of semantic ascent. Whereas SNOW IS WHITE is directly about the color of a worldly kind of object, 'SNOW IS WHITE' IS TRUE is a step removed from the world, as it introduces a truth-bearer and its features. But there is no reason to read the semantically ascended claim as one that assigns a metaphysically robust property to the truth-bearer in question. Quine goes unnecessarily far in declaring that calling 'Snow is white' true is tantamount to calling snow white (1970: 12). The mental act of predicating a color of a kind of object is not identical to the mental act of predicating a semantic property of a truth-bearer. Nevertheless, though the conceptual contents of SNOW IS WHITE and 'SNOW IS WHITE' IS TRUE are distinct, their metaphysical bases are not interestingly different. Necessarily, they share the same truth value (at least if the meaning of 'Snow is white' is held fixed). Whatever makes one true makes true the other as well. (Provided, at 
least, the existence of the truth-bearer in question.) Whatever it takes to make it be the case that snow is white is enough to make it the case that claims to that effect are true.

In sum, my view is that TRUTH can contribute to the composition of propositional thoughts in at least two distinct ways. First, it plays a logical-structural role in every propositional thought. This is reflected in ordinary language by the equivalence between saying ' $p$ ' and saying 'It's true that $p$ '. Secondly, TRUTH can also contribute to the ordinary content of a propositional thought, as when truth is predicated of a truth-bearer. The content it adds, on my view, is rather thin-it's not enough to change the "metaphysics" involved. As deflationists have pointed out, 'true' enables us to engage in semantic ascent (and generalizations, blind ascriptions, etc.) which is all we're really doing when we use truth as a predicate. What I object to in the deflationist program is that the only function of TRUTH is to enable semantic ascent and descent.

\subsubsection{Objections}

At this point, it might be wise to consider some opposition to the view. My thesis- that TRUTH belongs to the composition of each and every propositional thought - is no modest one, and perhaps has yet to be sufficiently motivated. So let me consider another defense of it by way of challenging opposing views, and thus offering an argument by elimination. If omnipresence is false, then there are two possible alternatives:

(C) TRUTH belongs to the composition of no propositional thought whatsoever.

(D) TRUTH belongs to the composition only of some proper subset of propositional thoughts.

I address these two views in turn. While I do not maintain that they can be refuted, I do find them less viable alternatives when compared to the omnipresence account.

Thesis $(\mathrm{C})$ coheres well with many deflationary ideas about truth. When deflationists maintain that truth is merely a linguistic or expressive device, or that the truth predicate is "logically superfluous" (Ayer 1950: 88), they may have in mind the idea that no thought's composition is in any way provided by TRUTH. Prosententialists, for example, see all uses of 'true' as being purely anaphoric: 'true' provides no meaning of its own, as its meaning is always parasitic on something else (e.g., Grover 1992). Advocates of (C) would, presumably, agree with me that SNOW IS WHITE 
and IT IS TRUE THAT SNOW IS WHITE are identical thoughts. However, whereas I see TRUTH contributing to both, deflationists maintain that it contributes to neither. ${ }^{12}$

The best challenge to $(\mathrm{C})$, it seems to me, draws on the fact that not all linguistic appeals to truth take the form of predications involving 'is true' or uses of the sentential prefix 'it is true that'. ${ }^{13}$ Consider Frege's claim that to assert a thought is to present it as being true (1979). Here, 'true' appears not as a predicate, and so cannot be disquoted away. After all, TO ASSERT A THOUGHT IS TO PRESENT IT AS BEING TRUE and TO ASSERT A THOUGHT IS TO PRESENT IT are different thoughts. The latter expresses the false view that all presentations of a thought are assertions. (One can, for example, present a thought as being worthy of consideration without thereby asserting it.) It doesn't matter whether or not Frege's view is true. What matters is that these are different thoughts, and so the role of 'true' in Frege's 'To assert a thought is to present it as being true' is not semantically idle, redundant, or superfluous. Or take 'The meaning of a sentence is given by the conditions under which it is true'. Again, this may or may not be true. But while its truth value is beside the point, its meaning isn't. A deflationist must offer some analysis of the thought being expressed that reveals that the sentence's prima facie appeal to truth is ultimately dispensable. The most obvious suggestion is something along the lines of 'For any sentence ' $p$ ', the meaning of ' $p$ ' is that $p$ '. It strikes me that this expresses a thought distinct from what the truth-conditional theorist of meaning is attempting to say. To advance the contentious thesis that meaning must be understood in terms of truth conditions is not simply to assert (as everyone should be willing to) that ' $p$ ' means that $p$. For one thing, truth conditions—at least as found in Davidsonian theories of meaning - are not in every case given disquotationally. Whatever one thinks of these particular examples, there need be only one truth-involving thought that evades deflationist analysis in order to falsify (C). There is good reason to suppose there are such counterexamples.

Occupying the rest of the space between the extremes represented by omnipresence and the deflationary never-present view of TRUTH is (D). (D), of course, could be made more precise in myriad ways. One might think (as with the lexical view) that TRUTH belongs to all and only thoughts expressed by sentences that employ 'true' and related words: TRUTH shows up in our

\footnotetext{
12 If deflationists think that TRUTH never contributes to the composition of thoughts, then, given the position that concepts are to be understood as the building blocks of thought, perhaps deflationists should maintain that TRUTH simply doesn't exist. There is no need to posit such a concept, since there is no thought-constituting role for it to play. There remains an expressive need for the word 'true', of course, but that is another matter. I leave it to deflationists to decide whether or not such a consequence is a tolerable addition to their view.

13 See also Simmons 2006 and Bar-On and Simmons 2007, from which I learned this argument.
} 
thoughts when (but only when) 'truth' shows up in our language. Alternatively, one might think that the proper subset in question is even smaller, formed simply by those thoughts I identified in the previous paragraph that defy deflationist analysis. Thus, this view might agree with deflationists that thoughts like IT IS TRUE THAT SNOW IS WHITE, despite appearances, make no use of TRUTH. Yet it would agree with me that TO ASSERT IS TO PRESENT AS TRUE does make use of TRUTH. There are many other versions of $(\mathrm{D})$, but these two precisifications are the most plausible and are in no way ad hoc.

I consider the less strict version first, which maintains that TRUTH only accompanies 'truth'. On this view, IT IS TRUE THAT SEVEN IS PRIME requires possession of TRUTH in order to be thought, but SEVEN IS PRIME does not. Hence, this version of (D) must reject the identity between thoughts that $p$ and thoughts that it is true that $p$, to which both I and deflationists subscribe. And I imagine that many people not already committed in the theory of truth will find this result rather agreeable, at least on first inspection. However, I find its initial plausibility to rest solely on the fact that 'It is true that $p$ ' is a more complex sentence form than is ' $p$. ${ }^{14}$ Understanding the former sentence, it is true, requires more cognitive resources than does understanding the latter. To wit, one must be competent with 'it is true that'. But we cannot assume that with greater linguistic power comes greater conceptual responsibility. Learning synonyms expands the range of sentences one may utter, but not the range of thoughts one may think. One might master a new language without thereby gaining a single new (non-semantic) propositional thought. ${ }^{15}$ There might be other examples. One might, for instance, think that sentences of the form ' $p$ or $q$ ' express the same thought as sentences of the form ' $q$ or $p$ '. If this example is not compelling, there are likely other candidates to be found. For new linguistic abilities to betray new conceptual abilities, we need independent evidence that the thoughts expressed by the new linguistic clothes are genuinely distinct from those thoughts expressed before. When one gains 'it is true that', what are the new thoughts to be entertained? To my mind, one cannot without contradiction assert that $p$ while denying that it is true that $p$. Imagining a world such that $p$ is no different than imagining a world such that it is true that $p$. (In fact, I find the description of asserting one without thereby asserting the other incoherent.) The defender of (D) would surely agree that thoughts that $p$ and thoughts that it is true that $p$ necessarily share the same truth value, but must contend that they nevertheless are distinct thoughts. This is a difficult route to take, since this kind of case is not assimilable to

\footnotetext{
14 This difference seems to be the driving force behind Künne’s objection to omnipresence (2003: 51).

15 Obviously, in learning a language one can formulate new thoughts that involve the objects of that language, such as how the English speaking Chinese learner becomes able to think thoughts that express <我是美國人' means the same thing as 'I am an American'>.
} 
other classic cases of necessarily equivalent but distinct thoughts such as THERE IS WATER IN THE OCEAN and THERE IS $\mathrm{H}_{2} \mathrm{O}$ IN THE OCEAN or even TRIANGLES HAVE THREE SIDES and TRIANGLES HAVE THREE ANGLES.

There is, ultimately, no definitive test to determine whether two sentences express the same thought. Still, I fail to see any difference in the relevant cases. One can always insist that there just is a difference, and that TRUTH adds something to thoughts that it is true that $p$ that is absent in thoughts that $p$. But as it stands, this response is just question begging. The challenge for the defender of (D) is to articulate, in a non-ad hoc way, what the difference is supposed to be. If thoughts that $p$ and thoughts that it is true that $p$ are different thoughts about reality, that difference should be available to be seen by all who can think them, just as we can easily appreciate the difference between LOIS LANE LOVES SUPERMAN and LOIS LANE LOVES CLARK KENT.

Furthermore, the defender of (D) must reckon with the explanation of truth's transparency. According to (D), the two sides of the various truth biconditionals-regardless of which of the many schemas is in question-express different thoughts. The simplest reason why we can seamlessly infer between $\langle p\rangle$ and $<$ It is true that $p>$ is that adding 'it is true that' to our sentences adds nothing to the thoughts we express. That might be because TRUTH simply has nothing to contribute (deflationism), or because its contribution is already present (omnipresence). Either explanation is more straightforward than the one that supposes that conceptual content is added via 'it is true that', even though that content fails to disrupt the necessary equivalence between $\langle p\rangle$ and $\langle$ It is true that $p>$. Those defending (D) face the challenge of explaining how 'true' manages to be transparent in spite of providing new, unique conceptual contributions to our thoughts.

Consider, then, the more restricted version of (D). ${ }^{16}$ This view agrees with my critique of deflationism above: sentences like 'To assert is to present as true' make use of non-deflationary applications of 'true', and this fact reveals that TRUTH funds part of the thought it expresses. However, deflationists are correct in finding no role for TRUTH in ordinary applications of truth like when we utter 'It is true that seven is prime' and 'Seven is prime' is true'.

The best way to challenge this perspective is to reflect on just how minimal of a role TRUTH plays in our thinking, according to this view. The claims that give deflationists trouble can be rather abstract thoughts - thoughts that fuel philosophical inquiry, for sure, but thoughts that one might not encounter very often in day to day life. So let's imagine a community that never bothers to entertain these thoughts that give deflationists trouble. In fact, let's imagine that the community

\footnotetext{
${ }^{16}$ But note that my criticisms here also apply to the earlier version of (D).
} 
never even bothers with a truth predicate at all. When they agree with each other, they repeat each other's words instead of saying 'That's true'. When they want to re-assert the smart thing Smart uttered the night before, but which they have in the meantime forgotten, they are out of luck. They can't say 'That smart thing Smart uttered last night is true'. They get along okay, albeit without some of the expressive conveniences we enjoy. For example, it takes them a rather long time to assert that there's at least one true sentence in Hegel's voluminous corpus.

What our imaginary community speaks is a language that lacks its own truth predicate. Deflationists have identified the expressive inconveniences of such a language. (And Tarski has identified how, given some other assumptions, this language avoids the liar paradox.) In spite of these limitations, this language is quite powerful. It's no good for doing its own semantics, but it can express nearly every other thought one might want to express. The members of this community might be expert quantum physicists, or deeply insightful moral psychologists. Recall, though, that the speakers of this language don't think thoughts like that to assert is to present as true, or that meaning is understood in terms of truth. They never think about semantics. Still, they can think about most everything else. According to the defender of (D), there is no reason to attribute the concept TRUTH to this community, for they never think the very particular set of thoughts for which TRUTH is necessary.

Is this the correct diagnosis, however? Think of all that this community can do. They have no problem forming beliefs; they have no hesitation making assertions or denials to one another. They engage in robust scientific inquiry, and know much about the world. They know the difference between describing the world and playing make-believe. Given a number of ordinary sentences, such as 'Snow is white', 'Snow is green', 'Grass is green', and 'Grass is white', they would have no trouble grouping the first and third together as the sentences that succeed in describing the world. (However, they might lack the predicate 'describe the world', understood as a truth predicate.) They would insist that the aim of science involves discovering that dinosaurs were the ancestors of birds only if dinosaurs were the ancestors of birds. They subscribe to the norm that one should believe that there are electrons only if there are electrons. Though they never use the word 'truth', they actually speak a language for which a Tarskian definition of truth can be offered, something which we cannot even claim for ourselves.

This community, in short, can do virtually everything we can do with the notion of truth, though they lack the predicate which grants us considerable expressive ease. They possess and deploy the ability to discriminate truth and falsity, though they never semantically ascend, as we do, in ways that would enable them to turn around and specifically predicate 'is true' and 'is false' of truth-bearers. Their cognitive abilities such as hypothesizing, denying, asserting, imagining, etc. 
are intact, though 'truth' does not reside in their lexicon. As a result, it strikes me as highly plausible that, although they lack the word 'true', they are in possession of TRUTH. To think otherwise is to suppose that TRUTH has very little to do in our thinking and cognitive activities. This would be quite surprising, given how tightly connected TRUTH appears to be to all sorts of cognitive and speech acts in which we engage all the time. The proponent of (D) must suppose that TRUTH is an incredibly esoteric concept, one that informs only certain particularly reflective propositional thoughts. (If one aims to diminish the cognitive importance of TRUTH so drastically, deflationism would seem to be the more plausible and principled option.) My view, by contrast, maintains that people have a concept of truth long before they ever engage in further reflective thought that concerns the connections between TRUTH and other notions. ${ }^{17}$ TRUTH is an ordinary (though unique!) concept, not an esoteric one, and among the most fundamental concepts we have.

4.2. What is the ontological status and nature of TRUTH?

I now hope to have motivated the omnipresence thesis, and shown how it renders TRUTH to be perhaps the single most important concept when it comes to propositional thought. It is, in Davidson's words, "the prime semantic concept; we could not think or speak in the sense of entertaining or communicating propositional contents without it" (2005: 155). With the argumentative work mostly accomplished by way of answering question (1), answers to the other core questions about TRUTH will follow quite naturally.

Let us turn, then, to the question of the ontology of TRUTH: what sort of object is it? Laurence and Margolis (1999) approach the ontology of concepts by wondering whether they are mental representations, abstract entities (such as Fregean senses), or something else, such as being a kind of behavioral or mental ability. I shall follow suit. Abstract concepts like TRUTH are not as easily assimilable to the representation model as are more ordinary concepts like BLUE and DUCK. We don't use TRUTH to classify truth-bearers as being either true or false, as we might use DUCK to sort animals into or out of Donald and Daffy's camp. That is to say, we don't inspect the intrinsic features of a judgment in order to determine its truth value (with the exception of tautologies and contradictions); instead we inspect the features of the objects the judgment is about. When we use

\footnotetext{
17 One issue I don't address here is how to understand the difference between mere possession of a concept and mastery of it. It might be that I'm correct that all proposition-users possess TRUTH, though mastery of it may result only after enormous practice, philosophical reflection, etc. If this is a tenable distinction, then my claim is the weaker one: propositional thought betrays possession, but not necessarily mastery, of TRUTH. Thanks to a referee for pushing me on this point.
} 
DUCK to classify Donald, we have done enough to know to classify $<$ Donald is a duck $>$ under TRUTH. There is no further step to be taken, to see whether the truth-bearer matches some mental representation offered by TRUTH. TRUTH is representationally idle when it comes to classifying truth-bearers by truth value. Besides, given TRUTH's structural-logical role in the composition of propositional thoughts, it belongs in a different category from ordinary concepts that give thoughts their non-logical content. So even if most concepts are mental representations, TRUTH is not. (Parallel remarks, I take it, apply to taking TRUTH to be a Fregean sense.)

Given the earlier investigation, it's clear that what is distinctive about TRUTH is that it enables us to have a fundamental cognitive ability: the ability to have propositional thoughts. TRUTH makes propositional thought possible. As a result, the simplest answer to the question of the ontology of TRUTH is that it is not a particular representational device, but rather an ability to engage in propositional thought. Understanding concepts as abilities is familiar in the work of philosophers such as Dummett (1993), who is skeptical of the explanatory fecundity in taking concepts to be mental representations. Dummett's ability view, then, is quite general. I, by contrast, have arrived at the view that TRUTH is an ability by exploring its specific role as a precursor for propositional thought, and not from any premises about what concepts in general must be. It may be that most other ordinary concepts fit the mental representation (or Fregean sense) model perfectly well; I have no horse in that race. If TRUTH is unique among concepts in being an ability, that is all the more ammunition for my overall hypothesis.

\subsection{What relations does TRUTH bear to 'true', 'truth', etc.?}

Assuming that the foregoing is on the right track, we can now appreciate some of the relations that obtain between TRUTH and its linguistic manifestations. One way to articulate the relationship is by claiming that TRUTH is prior to 'true'. In other words, one can be in full possession of TRUTH while lacking 'true' (and, of course, any of its synonyms from other languages). Furthermore, in line with the omnipresence thesis, thoughts can be composed by TRUTH even though 'true' never appears in the words that express them. When 'true' or 'truth' do make their appearance, they perform various functions. First, the sentential prefix 'it is true that' is genuinely redundant, and serves to make explicit the fact that all propositional thoughts are making a claim regarding truth. The claim that $p$ just is the claim that it is true that $p$. Second, the predicate 'is true' is used to enable semantic ascent, to allow us to indirectly talk about the world by way of talking about truth-bearers. In so doing, we are "changing the subject". Predicating truth of truth-bearers is different than directly talking about the world, and so TRUTH plays its double- 
duty role in such cases. ${ }^{18}$ Finally, sometimes 'true' appears to help articulate conceptual connections between TRUTH and other concepts, as in 'To assert is to present as true'.

This perspective on the relationship between TRUTH and 'true' is clearly articulated by Frege. To assert some truth—-to present the thought as in fact being true- - one doesn't need 'true' at all: "the assertion is not to be found in the word 'true', but in the assertoric force with which the sentence is uttered" (1979: 251). The speakers of our 'true'-free language above have no trouble asserting their beliefs, because they don't need 'true' to do so. It's their grasp of assertoric force that reveals their competence with TRUTH. In presenting a thought as being true, it is neither necessary nor sufficient that 'true' ever appear in our words.

What's less noticed is that Tarski's work on truth (1956) also motivates this Fregean perspective. What's striking about Tarski's view of truth is that the only sort of language for which a truth predicate can be non-paradoxically defined is a language which does not possess its own truth predicate. As soon as a language has a truth predicate that applies to itself, liar paradoxes can be generated. Hence, the only languages where truth can be successfully defined are languages which don't contain 'true' at all. To take a very simple case, imagine a language $\mathrm{L}$ with two sentences, ' $\Phi$ ' and ' $\Psi$ '. If ' $\Phi$ ' means that snow is white, and ' $\Psi$ ' means that grass is green, then we can define 'true-in-L' by way of conjoining ' $\Phi$ ' is true-in- $\mathrm{L}$ if and only if snow is white' and ' $\Psi$ ' is true-in- $\mathrm{L}$ if and only if grass is green'. Hence, Tarski can be interpreted as maintaining that TRUTH can be operant in a language, even if a truth predicate isn't. The community described above makes this idea manifest. They understand what truth is, how it differs from falsity, and how it relates to other notions, even if they can't articulate these ideas using 'truth' or 'true'. Frege and Tarski are united, alongside me, in thinking that TRUTH is prior to 'truth'. ${ }^{19}$

\footnotetext{
18 To see why, suppose I ask someone to tell me three features of the sentence 'Snow is white', and I receive the following reply: 'The sentence 'Snow is white' is in English, fewer than five words long, and true'. By my lights, the mission has been accomplished. On other views, the respondent has failed to reply to the task at hand, since in calling the sentence true, the sentence has somehow been left behind and a claim about snow has been asserted in its place. In effect, the reply is understood as 'The sentence 'Snow is white' is in English, fewer than five words long, and snow is white'. I find this an implausible understanding of the use of 'true' here, and a demonstration of why Field's "pure disquotational truth" predicate does not belong to any natural language, a conclusion with which he may agree (1994: 266). (I also see this as an argument against prosententialism.) A sentence about a sentence is not cognitively equivalent to any sentence that is not about a sentence.

${ }^{19}$ See Asay 2013 for more thoroughgoing discussion of how Tarski and Frege connect to the views adumbrated here.
} 
Questions about the structure of concepts are no less controversial than other questions about their nature. Though I do not have views about the structure of concepts in general, it will be worthwhile to briefly consider how TRUTH doesn't fit well with many familiar accounts.

The "classical" theory of concepts is that their structure is given in the form of a definition. Whether such definitions are available is contentious (I argue in Asay 2013 that no such definition of TRUTH is available), and the success of this sort of account of conceptual structure turns on the plausibility of any candidate definition. Other views, in many cases inspired by Wittgenstein, eschew definitions in favor of the notion of family resemblance: what unites the objects of concern to a particular concept are the variety of overlapping features that can be used to characterize a particular class. I am not sure how to develop a plausible version of this view with respect to TRUTH. The truths constitute half of our possible judgments. In many cases, there is no resemblance to be found between truths. Take 'Snow is white' and 'It's possible that Obama believes that the Twins will win the next World Series'. Their truth lies in snow's being white and the possibility that Obama believes in the Twins winning the next World Series. Given that the set of truths covers the entirety of possible thoughts, there is no hope whatsoever of finding traits of family resemblance that capture large swaths of them.

Similar thoughts pose challenges for other views of concepts familiar from the psychological literature. Prototype theories about concepts rely on there being some set of features belonging to most truths, in virtue of which we identify them as such. But what are the prototypical features of truths? The class of truths is far too vast and diverse for there to be any hope of finding such properties. Moreover, true judgments can be much more similar to false judgments than to other true judgments. Compare the similarity between THE WORLD POPULATION IS OVER 7 BILLION on the one hand, and THE WORLD POPULATION IS UNDER 7 BILLION and 2 IS THE ONLY EVEN PRIME NUMBER on the other. Besides, it's a mistake to think that TRUTH is used as a classificatory concept in this way. We assign a judgment as true not because of the features of judgment itself, but because of what that judgment is about.

An exemplar theory of concepts with respect to truth would rely on there being some privileged set of paradigm truths which we use in our deployment of TRUTH. What would be an exemplar of truth? <Snow is white> might be an example, if truth theorists' choice of a go-to example is any indication. But if so, what good would such exemplars be in my wondering whether $<$ Newtonian mechanics is false $>$ is true? To wonder whether $<$ Newtonian mechanics is false $>$ is 
true is to wonder about the merits of Newtonian mechanics; its relationship to distinct truths, however exemplary, is of no use at all.

The difference between TRUTH and many other familiar concepts is easy to appreciate. TRUTH doesn't earn its keep in our cognitive economy by way of its classifying powers. We don't use TRUTH in order to identify truths. To identify $<$ Snow is white $>$ as true, we need to identify snow as being white. Once we do that, it's a simple semantic ascent to seeing $<$ Snow is white $>$ as being true. Hence, it makes sense why TRUTH doesn't fit into theories of concepts that are designed around understanding how we go about classifying the objects of our experience. When a thought is true, its truth is the result of what's going on in the world, and not necessarily what features the thought itself has. (Contradictions and tautologies again being the exception.) $<$ Snow is white $>$ is true in virtue of the color of snow, not in virtue of the properties of $<$ Snow is white $>$. We determine that Snoopy is a dog by inspecting Snoopy and the features intrinsic to him; hence the prospects for an exemplar or prototype theory of DOG are good. Studying the intrinsic features of $<$ Snow is white $>$ or 'Snow is white' will not help us determine whether or not truth applies to them. TRUTH has a different role to play. As a result, the right place to look for a theory of the structure of TRUTH is not the usual, familiar theories of interest to psychologists and philosophers of psychology. TRUTH is better thought of as a logical or structural concept, one that is a prerequisite for forming propositional thoughts, not (in the first instance) an ordinary component of propositional thoughts. As noted above, I do not have a theory of the nature of logical-structural concepts to offer at this time, but I do believe we make progress in our understanding of TRUTH by seeing how it demonstrates the need for considering a different form of conceptual structure. Not all concepts fit the classificatory mold.

\subsection{What is involved in possessing TRUTH?}

According to Christopher Peacocke, "A theory of concepts should be a theory of concept possession" (1992: 5). If so, then my theory of the concept TRUTH can be simply stated: to possess TRUTH is to possess the ability to think propositional thoughts. To determine if someone has the concept TRUTH, study what the person does, not just what he or she says. One may possess TRUTH even if one doesn't possess 'truth', as what constitutes possession of the former is being able to think any propositional thought at all, not just those that are, on the surface, "about" truth.

Perhaps the most explicit competing account of TRUTH possession is found in Horwich's minimalism: "The concept of truth (i.e. what is meant by the word 'true') is that constituent of belief states expressed in uses of the word by those who understand it-i.e. by those whose use of 
it is governed by the equivalence schema" (1998: 37). He continues: "the meaning of 'true' is constituted by our disposition to accept those instances of the truth schemata that we can formulate" (1998: 128). For Horwich, to possess TRUTH is to be disposed to accept biconditionals of the form 'The proposition that $p$ is true if and only if $p$ '. On Horwich's view, TRUTH is accounted for by finding the meaning of 'true', which in turn is determined by the behavior of those who wield 'true'. Horwich identifies the propositional truth schema as providing the key to understanding the meaning of 'true'. Anyone disposed to accept the instances of the propositional truth schema thereby possesses TRUTH.

The contrast with my view should be clear. For Horwich, a necessary condition for possessing TRUTH is possessing 'true' and a disposition to accept certain equivalences involving it. As a result, Horwich is committed to claiming that anyone who lacks a truth predicate (including the speakers of our imaginary community) cannot possess the concept of truth. As I argued above, this consequence is implausible. Communities of speakers who are capable of far more advanced thought than us, and who can engage in nearly all the cognitive activities that we can are possessed of TRUTH. This concept is at work when they form beliefs, express those beliefs, play make-believe, and scientifically investigate the world. Horwich may insist nevertheless that if they don't possess 'true', they don't possess TRUTH. What remains unclear, though, is why we should accept that conceptual possession is so dependent in this case on linguistic possession. It is no general truth that to have a concept one must first have a language. Otherwise non-linguistic animals could not have any concepts, which (even if true) is not obviously true. If we are willing to separate concept possession from word possession, then accounts of the former are not so dependent on the latter, as Horwich's view must maintain. The right lesson to draw from Tarski, I maintain, is that we don't need 'true' in order to think and talk about truth.

Nevertheless, one might agree with me that while possessing 'true' is not necessary for possessing TRUTH, I have still misidentified the ability that TRUTH confers. Merely being able to form propositional thoughts might seem too weak a requirement for TRUTH possession, seeing as how it requires TRUTH to be possessed, most likely, by many animals, infants, and small children. If the ability to token propositional thoughts is too weak, and the ability to semantically ascend is too strong, what other view might be available? A plausible candidate that has been suggested to me is the ability, much studied by developmental psychologists, to attribute false beliefs to others. ${ }^{20}$ There is much to recommend about this view. First, it stays close to my approach of looking for TRUTH by investigating what people are able to do, not just say. Second, it identifies a cognitive

\footnotetext{
20 Thanks go to Max Deutsch and Dorit Bar-On for helpful discussion of this suggestion.
} 
ability closely connected to TRUTH, seeing as how identifying others' beliefs as being false is a clear case of a truth-theoretic cognitive ability. One cannot assign falsity to another's belief unless one recognizes that one has a competing belief that one takes to be true. One needs FALSITY, and so TRUTH, to attribute false beliefs, and so when children are able to pass the false belief task (around age four), they have acquired TRUTH.

While I agree that children need TRUTH to pass the false belief task (i.e., understanding that people have beliefs different from their own), I disagree that gaining the ability to pass the test is constitutive of possessing TRUTH. One reason to think that TRUTH appears only at this later stage is that this newly mastered skill shows that children can now tell the difference between truth and falsity, which is necessary for possessing TRUTH. But children can distinguish truth and falsity long before they learn the specialized mindreading skills that inform the false belief task. Children don't believe everything they hear or think prior to age four; they make judgments about what is true and false before that. What's more, children are able to assign beliefs to others, even if those assignments do not vary from their own. This ability shows that children possess BELIEF even before passing the false belief task, which to me also indicates that they possess TRUTH; you cannot understand what it is to believe something without at the same time understanding what it is for something to be true. What passing the false belief task is indicative of is a new adroitness in understanding alternative perspectives; we should not conflate the ability to detect truth and falsity in others' beliefs with the ability for understanding truth and falsity in our own. The latter, less demanding, ability already requires TRUTH. ${ }^{21}$

\section{Conclusion: Empirical Connections}

My contention has been that TRUTH is a concept unlike any other. I have tried to explicate and defend the Fregean idea that TRUTH forms part of the constitution of any propositional thought whatsoever. TRUTH, on this view, is a concept that we must possess if we are to think anything that can be true or false of the world. To see who possesses TRUTH, we cannot merely attend to those who possess 'true'; we must look to those who can engage with the truth.

It's worth noting that by divorcing TRUTH from 'truth' and 'true', I have not rendered unempirical the question of who has the concept of truth. ${ }^{22}$ Horwich, it is true, offers a straightforward empirical account of TRUTH possession, but his is not the only one. It's an

\footnotetext{
21 See also Mascaro and Morin 2015, which explores very young children's abilities vis-à-vis truth and falsity, and finds them from a very young age.

22 Thanks go to Jake Beck and Max Deutsch here for identifying some different aspects of this issue.
} 
empirical question as to which beings are able to form propositional thoughts, and so it's an empirical question on my view as well as to which beings possess TRUTH. I leave it to psychologists to lead the way in showing how to demonstrate which beings are capable of forming propositional thoughts (though I do not hesitate to add that the question of how one identifies the formation of a propositional thought in a being is already a philosophy-laden matter). My view predicts that humans (and perhaps many animals) possess TRUTH from a very early age, if not birth (or before). There is at least some psychological precedent for this view. Lawrence Barsalou has argued that infants acquire the "experiential basis" for concepts like TRUTH long before they acquire language. He writes that an infant

constantly experiences the event sequence that underlies truth, falsity, negation, anger, and their related concepts. From birth, and perhaps before, the infant simulates its expected experience and assesses whether these simulations map successfully into what actually occurs. As an infant experiences this event sequence day after day, it learns about satisfied versus failed expectations. If infants have the schematic symbol formation process described earlier, and if they can apply it to their introspective experience, they should acquire implicit understandings of truth, falsity, and negation long before they begin acquiring language. (1999: 602)

Connecting my views with actual work in empirical psychology will, of course, take much further analysis. For instance, Barsalou focuses on the having of expectations and the ability to appreciate their being satisfied or not; his view is that a cognitive ability of that sort can provide the basis for possessing TRUTH. A productive line of inquiry would involve studying how compatible his view is with my own: the ability he identifies may well be an instance of the ability that I have identified. But regardless of that specific compatibility, it should be clear that my approach to TRUTH suggests a methodology for working together with empirical psychologists. I offer a view of what it would take to possess TRUTH, as a particular kind of cognitive ability, and psychologists then discover when that ability surfaces. ${ }^{23}$

All told, my view about the nature of TRUTH might pose problems for general views of concepts that maintain that concepts are always to be understood along the lines of definitions, prototypes, or exemplars. Perhaps a more heterogeneous account of the nature of concepts is

\footnotetext{
23 Hence, I see my approach here as fitting what Peacocke has identified as the "simple account" of the relation between philosophical and psychological accounts of concepts (1992: 177-178). See Machery 2009: 38-47 for criticism of this view.
} 
called for. (This is not news—see, e.g., chapter 3 of Machery 2009.) But my view is not antagonistic towards the philosophical or empirical study of concepts. To the contrary, it shows that some concepts deserve special attention. If concepts are the building blocks of thought, then it's no surprise that some of them are particularly foundational to our thought. TRUTH is one such foundation.

\section{Acknowledgments}

I would like to thank the New York Philosophy of Language Workshop and the Department of Philosophy at the University of Connecticut, where versions of this paper were presented in April 2015. Special thanks go to Dorit Bar-On, Max Deutsch, Friederike Moltmann, Matt Moss, and Keith Simmons for their stimulating discussion with me on these matters, and to Jeremy Wyatt for his extensive comments. Finally, thanks go to the referees for the journal, who offered very substantial feedback. The research in this paper was supported by a grant from the Research Grants Council of the Hong Kong Special Administrative Region, China (HKU 23400014).

\section{References}

Alston, William P. 1996. A Realist Conception of Truth. Ithaca: Cornell University Press.

—. 2002. Truth: concept and property. In What is Truth?, ed. Richard Schantz, 11-26. Berlin: Walter de Gruyter.

Asay, Jamin. 2013. The Primitivist Theory of Truth. Cambridge: Cambridge University Press.

—. 2014. Against truth. Erkenntnis 79: 147-164.

Ayer, Alfred Jules. 1950. Language, Truth, and Logic. Second edition. London: Victor Gollancz.

Bar-On, Dorit, Claire Horisk, and William G. Lycan. 2000. Deflationism, meaning and truthconditions. Philosophical Studies 101: 1-28.

Bar-On, Dorit, and Keith Simmons. 2007. The use of force against deflationism: assertion and truth. In Truth and Speech Acts: Studies in the Philosophy of Language, eds. Dirk Greimann and Geo Siegwart, 61-89. London: Routledge.

Barsalou, Lawrence W. 1999. Perceptual symbol systems. Behavioral and Brain Sciences 22: 577-660.

Blackburn, Simon. 1984. Spreading the Word: Groundings in the Philosophy of Language. Oxford: Clarendon Press.

Boghossian, Paul. 2010. Our grasp of the concept of truth: reflections on Künne. dialectica 64: 553563. 
Davidson, Donald. 1996. The folly of trying to define truth. Journal of Philosophy 93: 263-278.

—. 2005. Truth and Predication. Cambridge: Belknap Press.

Dummett, Michael. 1993. The Seas of Language. Oxford: Clarendon Press.

Edwards, Douglas. 2013. Truth as a substantive property. Australasian Journal of Philosophy 91: 279294.

Field, Hartry. 1994. Deflationist views of meaning and content. Mind (New Series) 103: 249-285.

Frege, Gottlob. 1879. Begriffsschrift: Eine der Arithmetischen Nachgebildete. Halle: Verlag von Louis Nebert.

—. 1952. On sense and reference. Trans. Max Black. In Translations from the Philosophical Writings of Gottlob Frege, eds. Peter Geach and Max Black, 56-78. Oxford: Basil Blackwell.

—. 1956. The thought: a logical inquiry. Trans. A. M. Quinton and Marcelle Quinton. Mind (New Series) 65: 289-311.

—. 1979. Posthumous Writings. Eds. Hans Hermes, Friedrich Kambartel, and Friedrich Kaulbach with the assistance of Gottfried Gabriel and Walburga Rödding, trans. Peter Long and Roger White, with the assistance of Raymond Hargreaves. Oxford: Basil Blackwell.

Grover, Dorothy. 1992. A Prosentential Theory of Truth. Princeton: Princeton University Press.

Horwich, Paul. 1998. Truth. Second edition. Oxford: Clarendon Press.

Kölbel, Max. 2008. "True” as ambiguous. Philosophy and Phenomenological Research 77: 359-384.

—. 2013. Should we be pluralists about truth? In Truth and Pluralism: Current Debates, eds. Nikolaj J. L. L. Pedersen and Cory D. Wright, 278-297. Oxford: Oxford University Press.

Künne, Wolfgang. 2003. Conceptions of Truth. Oxford: Clarendon Press.

—. 2008. Frege on truths, truth and the true. Studia Philosophica Estonica 1: 5-42.

Laurence, Stephen, and Eric Margolis. 1999. Concepts and cognitive science. In their Concepts: Core Readings, 3-81. Cambridge, MA: MIT Press.

Lewis, David. 1983. New work for a theory of universals. Australasian Journal of Philosophy 61: 343377.

Lynch, Michael P. 2009. Truth as One and Many. Oxford: Clarendon Press.

Machery, Edouard. 2009. Doing without Concepts. Oxford: Oxford University Press.

Margolis, Eric, and Stephen Laurence. Concepts. The Stanford Encyclopedia of Philosophy (Spring 2014 Edition), ed. Edward N. Zalta. URL = $<$ https://plato.stanford.edu/archives/spr2014/entries/concepts/>.

Mascaro, Olivier, and Olivier Morin. 2015. Epistemology for beginners: two- to five-year old children's representation of falsity. PLOS ONE 10: 1-20. 
McGinn, Colin. 2000. Logical Properties: Identity, Existence, Predication, Necessity, Truth. Oxford: Clarendon Press.

Moore, George Edward. 1903. Principia Ethica. Cambridge: Cambridge University Press.

Patterson, Douglas. 2010. Truth as conceptually primitive. In New Waves in Truth, eds. Cory D. Wright and Nikolaj J. L. L. Pedersen, 13-29. New York: Palgrave Macmillan.

Peacocke, Christopher. 1992. A Study of Concepts. Cambridge, MA: Bradford Books.

Prinz, Jesse J. 2002. Furnishing the Mind: Concepts and their Perceptual Basis. Cambridge, MA: Bradford Books.

Quine, W. V. 1970. Philosophy of Logic. Englewood Cliffs, NJ: Prentice-Hall.

Read, Stephen. 2002. The liar paradox from John Buridan back to Thomas Bradwardine. Vivarium 40: 189-218.

Salmon, Nathan. 1986. Frege's Puzzle. Cambridge: Bradford Books.

Scharp, Kevin. 2013. Replacing Truth. Oxford: Oxford University Press.

Schiffer, Stephen. 2003. The Things We Mean. Oxford: Clarendon Press.

Simmons, Keith. 2006. Deflationism and the autonomy of truth. Philosophy and Phenomenological Research 72: 196-204.

Sosa, Ernest. 1993. The truth of modest realism. Philosophical Issues 3: 177-195.

Stalnaker, Robert. 1976. Propositions. In A.F. MacKay and D. D. Merrill, eds., Issues in the Philosophy of Language, 79-91. New Haven: Yale University Press.

Strawson, P. F. 1949. Truth. Analysis 9: 83-97.

Tarski, Alfred. 1956. The concept of truth in formalized language. In his Logic, Semantics, Metamathematics: Papers From 1923 to 1938, trans. J. H. Woodger, 152-278. Oxford: Clarendon Press.

Wright, Crispin. 1992. Truth and Objectivity. Cambridge: Harvard University Press.

—. 1996. Response to commentators. Philosophy and Phenomenological Research 56: 911-941.

—. 2013. A plurality of pluralisms. In Truth and Pluralism: Current Debates, eds. Nikolaj J. L. L. Pedersen and Cory D. Wright, 123-153. Oxford: Oxford University Press. 